\title{
Improvement in Near Vision Following Silodosin Treatment in Patients With Lower Urinary Tract Symptoms
}

\author{
Hyun Jin Shin ${ }^{1}$, Woo Suk Choi ${ }^{2}$, Shin-Hyo Lee ${ }^{3}$, Andrew G. Lee ${ }^{4,5,6,7,8,9,10,11}$, Aram Kim² ${ }^{2}$ Hyoung Keun Park ${ }^{2}$, Sung Hyun Paick², \\ Hyeong Gon Kim² \\ ${ }^{1}$ Department of Ophthalmology, Research Institute of Medical Science, Konkuk University Medical Center, Konkuk University School of Medicine, Seoul, \\ Korea \\ ${ }^{2}$ Department of Urology, Konkuk University School of Medicine, Seoul, Korea \\ ${ }^{3}$ Department of Anatomy, Yonsei University College of Medicine, Seoul, Korea \\ ${ }^{4}$ Department of Ophthalmology, Blanton Eye Institute, Houston Methodist Hospital, Houston, TX, USA \\ ${ }^{5}$ Department of Ophthalmology, Neurology, Neurosurgery, Weill Cornell Medicine, New York, NY, USA \\ ${ }^{6}$ Department of Ophthalmology, University of Texas Medical Branch, Galveston, TX, USA \\ ${ }^{7}$ Department of Ophthalmology, UT MD Anderson Cancer Center, Houston, TX, USA \\ ${ }^{8}$ Department of Ophthalmology, Texas A and M College of Medicine, College Station, TX, USA \\ ${ }^{9}$ Department of Ophthalmology, University of Iowa Hospitals and Clinics, Iowa City, IA, USA \\ ${ }^{10}$ Department of Ophthalmology, Baylor College of Medicine and the Center for Space Medicine, Houston, TX, USA \\ ${ }^{11}$ Department of Ophthalmology, University of Buffalo, Buffalo, NY, USA
}

Purpose: The objective of this study was to investigate the change in near visual function after the administration of oral silodosin to patients with lower urinary tract symptoms (LUTS).

Methods: This prospective study included treatment-naive patients who were scheduled to start treatment with silodosin for LUTS. A comprehensive ophthalmological evaluation including the near vision and the automated pupillometry was performed at baseline and after 3 months of silodosin treatment. For subjective assessment of near visual ability and satisfaction, a Near Activity Visual Questionnaire-10 (NAVQ-10) was also used at the same time (higher scores indicating worse quality). Results: Of 23 patients enrolled in this study, 15 continued with silodosin (8 mg once daily) treatment for 3 months and completed a follow-up evaluation. The mean age of participants was $60.4 \pm 8.4$ years. Distant visual acuity and spherical error were unchanged after silodosin treatment. However, near vision acuity (logMAR) was improved after treatment (right, $0.47 \pm 0.36$ vs. $0.38 \pm 0.39, \mathrm{P}=0.018$; left, $0.41 \pm 0.37$ vs. $0.31 \pm 0.34, \mathrm{P}=0.068$; both, $0.27 \pm 0.26$ vs. $0.21 \pm 0.27, \mathrm{P}=0.043$ ). Pupil size under room light decreased significantly in both eyes (right, $3.77 \pm 0.60$ vs. $3.16 \pm 0.58, \mathrm{P}=0.001$; left, $3.72 \pm 0.80$ vs. $3.21 \pm 0.75$, $\mathrm{P}=0.002)$. The Rasch scale at NAVQ-10 improved from $54.7 \pm 9.9$ to $48.5 \pm 11.2(\mathrm{P}=0.004)$.

Conclusions: This preliminary study demonstrated that highly selective alpha-1A adrenergic receptor antagonists such as silodosin improve near visual acuity and quality in patients with LUTS/benign prostatic hyperplasia. Decrease in pupil size caused by inhibition of adrenergic alpha 1 mediated contraction of iris dilator muscle is a possible mechanism underlying improved near vision.

Keywords: Silodosin; Receptors, adrenergic, alpha-1; Myopia; Presbyopia; Pupil

- Fund/Grant Support: This work was supported by Konkuk University Medical Center Research Grant 2017.

- Research Ethics: This study was approved by the Institutional Review Board (IRB)/Ethics Committee at Konkuk University Medical Center (registration number: KUH 1130056). The study was conducted according to the tenets of the Declaration of Helsinki after written informed consent of the patients.

- Conflict of Interest: No potential conflict of interest relevant to this article was reported.

Corresponding author: Woo Suk Choi (i) https://orcid.org/0000-0002-8352-578X Department of Urology, Konkuk University Hospital, Konkuk University School of Medicine, 120-1 Neungdong-ro, Gwangjin-gu, Seoul 05030, Korea Email: 20140123@kuh.ac.kr

Submitted: July 9, 2020 / Accepted after revision: October 12, 2020
This is an Open Access article distributed under the terms of the Creative Commons Attribution Non-Commercial License (https://creativecommons.org/licenses/by-nc/4.0/) which permits unrestricted non-commercial use, distribution, and reproduction in any medium, provided the original work is properly cited. 


\section{INTRODUCTION}

Lower urinary tract symptoms (LUTS) are often related to benign prostatic hyperplasia (BPH) in elderly men [1]. The prevalence of $\mathrm{BPH}$ as a histological diagnosis increases from $25 \%$ among men in their 40 s to more than $80 \%$ among men in their 70 s [2]. The prevalence of LUTS in men in general varies from $64 \%$ to $72 \%$ [3]. Presbyopia, defined as age-related impairment in near vision due to the progressive loss of the accommodative ability of the eye is common and affects virtually every individual older than 50 to 60 years [4-6]. In one study, an estimated 1.8 billion cases of presbyopia were reported worldwide in 2015 [7].

Although LUTS/BPH and presbyopia are both age-related conditions they do not share pathophysiology. One study however noted that $20 \%$ of presbyopic patients treated for LUTS/ $\mathrm{BPH}$ with silodosin had visual changes during screening of systemic adverse events [8]. One study author reported anecdotally that the near vision seemed to improve in some patients who were treated with silodosin for LUTS/BPH.

Silodosin is a highly selective alpha-1A adrenergic receptor antagonist and is a primary treatment for LUTS/BPH [9]. Alpha-1 adrenergic receptors exist not only in prostate but also in ocular tissue such as iris, retina, and choroid [10,11]. Alpha-1 adrenergic receptor antagonists inhibit the adrenergic contraction of iris dilator muscle, resulting in miosis $[12,13]$. Miosis can reduce optical aberrations (pinhole effect) and improve the depth of focus [14].

We hypothesized that silodosin might improve near vision in phakic patients with presbyopia by increasing the depth of focus. To date, the effect of alpha-1A adrenergic receptor antagonist on near visual function has not been previously investigated. Therefore, to evaluate this hypothesis, we prospectively investigated the change in near visual function after treatment of naive patient with silodosin for LUTS/BPH.

\section{MATERIALS AND METHODS}

This study was a prospective, observational study conducted at the Department of Urology and Ophthalmology at Konkuk University Medical Center, Seoul, Korea between December 2017 and April 2019. This clinical study was approved by the Institutional Review Board (IRB)/Ethics Committee at Konkuk University Medical Center (registration number: KUH 1130056). The study was conducted according to the tenets of the Decla- ration of Helsinki after written informed consent of the patients. The study subjects included patients who were scheduled to start silodosin for the treatment of LUTS/BPH. Patients were evaluated for LUTS/BPH via urinalysis, measurement of prostate-specific antigen (PSA), transrectal ultrasonography, uroflowmetry, International Prostate Symptom Score (IPSS) questionnaire, and overactive bladder symptom score questionnaires. Voiding diaries were obtained when storage symptom was obvious. The clinical indications for silodosin treatment were IPSS greater than 8 points, a maximum flow rate below 15 $\mathrm{mL} / \mathrm{sec}$ on uroflowmetry, and patients who showed possible ejaculatory dysfunction. This evaluation and treatment decisions were conducted routinely by the urology department and were not part of the study procedure. All patients received silodosin $8 \mathrm{mg}$ once daily for 3 months.

\section{Participant Enrollment}

The study inclusion criteria were as follows: (1) agreement to participate in the study protocol, (2) men aged $>40$ years, (3) planning to start silodosin treatment, (4) self-reported difficulty seeing at the usual near working distance, (5) near emmetropes with a mean spherical error not greater than \pm 0.50 diopter (D) with/without glasses. Exclusion criteria were: (1) previous or current medications for LUTS/BPH or overactive bladder, including alpha-adrenergic receptor inhibitors, 5 alpha-reductase inhibitors, or antimuscarinic agents, (2) history of neurogenic bladder, (3) cataracts, graded at more than nuclear opalescence 3 or posterior subcapsular opacity 3 according to the Lens Opacity Classification Scheme, (4) any major ocular motor imbalance or ocular pathology, (5) near or distance visual disturbance due to neurophysiological disorder, (6) history of cerebrovascular disease, and (7) treatment with medications known to affect muscle tension or autonomic nervous system, including antipsychotics or antidepressant.

\section{Ophthalmologic Evaluation}

All patients were subjected to comprehensive ophthalmological evaluation. Ophthalmic examinations were: (1) visual acuity measurement at near and at distance using a near vision acuity (logMAR) chart, (2) manifest refraction based on retinoscopy, (3) intraocular pressure measurement, (4) slit lamp biomicroscopy, (5) indirect fundus examination, (6) pupil size measurements under room light using an infrared quantitative pupilometer (Neuroptics Inc, Irvine, CA, USA), (7) binocular vision and alignment testing via alternating cover test, and (8) near 
stereoacuity using the Titmus stereotest (Titmus, Optical Co., Inc., Chicago, IL, USA). All the examinations were conducted at baseline and after 3 months of silodosin treatment under the same condition.

\section{Near Vision Questionnaire}

Near Activity Visual Questionnaire-10 (NAVQ-10) is a 10-item short questionnaire for the evaluation of subjective near visual ability and satisfaction (Table 1 ) $[15,16]$. The questionnaire was assigned a 4-point Likert scale with responses including 'no difficulty', 'a little difficulty', 'moderate difficulty', and 'extreme difficulty or stopped this activity due to vision.' Raw response scores were converted to a 0-100 Rasch scale with higher scores indicating worse quality. General satisfaction was evaluated using an additional item 11: "Do you think your overall near vision improved after taking the medication?". Item 11 was also rated on a 5-point scale based on the following responses: 'no change,' 'a little change,' 'moderate change,' 'marked change,' and 'ex- treme change'.

\section{Main Outcome Measures}

The outcome measures were change in spherical error, pupil size, improvement in near visual acuity, near stereopsis, and NAVQ-10.

\section{Statistical Analysis}

All statistical analyses were performed using IBM SPSS Statistics ver. 19.0 (IBM Co., Armonk, NY, USA). Data are presented as mean \pm standard deviation and median (interquartile range). Statistically significant differences between variables at baseline and 3 months after silodosin treatment were determined using the Wilcoxon signed-rank test for nonparametric values. The Chi-square test was used to compare categorical data. A P-value of $<0.05$ was considered statistically significant.

Table 1. Change in Near Activity Visual Questionnaire-10 following 3 months of treatment with silodosin

\begin{tabular}{|c|c|c|c|c|c|}
\hline \multirow{2}{*}{ Near vision QoL questionnaires } & \multicolumn{2}{|c|}{ Baseline } & \multicolumn{2}{|c|}{3 Months } & \multirow{2}{*}{ P-value } \\
\hline & Mean \pm SD & Median (IQR) & Mean \pm SD & Median (IQR) & \\
\hline $\begin{array}{l}\text { 1. Reading small print, such as newspaper articles, items } \\
\text { on a menu, and telephone directories }\end{array}$ & $1.9 \pm 0.6$ & $2.0(2.0-2.0)$ & $1.5 \pm 0.9$ & $2.0(1.0-2.0)$ & $0.028^{*}$ \\
\hline $\begin{array}{l}\text { 2. Reading labels/instructions/ingredients/prices, such as } \\
\text { those on medicine bottles, food packaging }\end{array}$ & $2.1 \pm 0.8$ & $2.0(1.25-3.0)$ & $1.8 \pm 0.8$ & $2.0(1.25-2.0)$ & 0.164 \\
\hline $\begin{array}{l}\text { 3. Reading your post/mail, such as electric bills, greeting } \\
\text { cards, bank statements, and letters from friends and } \\
\text { family }\end{array}$ & $1.9 \pm 0.7$ & $2.0(1.25-2.0)$ & $1.4 \pm 0.9$ & $1.0(1.0-2.0)$ & $0.006^{*}$ \\
\hline $\begin{array}{l}\text { 4. Writing and reading your own writing, such as greeting } \\
\text { cards, notes, letters, filling in forms, checks, and signing } \\
\text { your name }\end{array}$ & $1.5 \pm 0.8$ & $1.0(1.0-2.0)$ & $1.2 \pm 0.6$ & $1.0(1.0-1.75)$ & 0.103 \\
\hline $\begin{array}{l}\text { 5. Seeing the display and keyboard on a computer or } \\
\text { calculator }\end{array}$ & $1.4 \pm 0.8$ & $1.0(1.0-2.0)$ & $1.1 \pm 0.8$ & $1.0(1.0-1.0)$ & 0.055 \\
\hline $\begin{array}{l}\text { 6. Seeing the display and keyboard on a mobile or fixed } \\
\text { telephone }\end{array}$ & $1.9 \pm 0.8$ & $2.0(1.0-2.75)$ & $1.4 \pm 0.7$ & $1.0(1.0-2.0)$ & $0.014^{\star}$ \\
\hline $\begin{array}{l}\text { 7. Seeing objects close to you and engaging in your } \\
\text { hobbies, such as playing card games, gardening, and } \\
\text { seeing photographs }\end{array}$ & $1.6 \pm 1.1$ & $1.0(1.0-2.75)$ & $1.2 \pm 0.9$ & $1.0(1.0-2.0)$ & 0.054 \\
\hline 8. Seeing objects close to you in poor or dim light? & $1.2 \pm 0.8$ & $1.0(1.0-1.75)$ & $1.2 \pm 0.9$ & $1.0(1.0-2.0)$ & 1.000 \\
\hline 9. Maintaining focus for prolonged near work & $1.5 \pm 0.9$ & $2.0(1.0-2.0)$ & $1.3 \pm 0.9$ & $1.0(1.0-2.0)$ & 0.217 \\
\hline 10. Conducting near work without spectacles & $1.7 \pm 0.7$ & $2.0(1.0-2.0)$ & $1.6 \pm 0.2$ & $2.0(1.0-2.0)$ & 0.164 \\
\hline Rasch scale (score, $0-100)^{\mathrm{b}}$ ) & $54.7 \pm 9.9$ & $57.0(48.9-61.6)$ & $48.5 \pm 11.2$ & $49.9(44.3-54.3)$ & $0.004^{*}$ \\
\hline
\end{tabular}

QoL, quality of life; SD, standard deviation; IQR, interquartile range.

${ }^{\star} \mathrm{P}<0.05$, statistically significant differences. ${ }^{\text {a) }} \mathrm{P}$-values were determined using Wilcoxon signed-rank test. ${ }^{\text {b) }} \mathrm{A}$ final score is calculated using a Rasch scale, which ranges from 0 (no difficulty) to 100 (extreme difficulty). 


\section{RESULTS}

A total of 23 patients were enrolled and evaluated. Of these 23 men, 15 patients met inclusion criteria for final analysis. The mean age of the patients was $60.4 \pm 8.4$ years. Consent withdrawal $(n=3)$, loss to follow-up $(n=3)$, discontinuation of medication before 1 month due to adverse event $(n=1)$, discontinuation of medication arbitrarily before 1 months $(n=1)$ were reasons for exclusion in the final analysis. Hypertension and diabetes were found in 4 (26.7\%) and 3 cases (20.0\%), respectively. The mean total prostate volume was $42.9 \pm 17.8 \mathrm{~mL}$. The transitional zone prostate volume was $18.5 \pm 12.5 \mathrm{~mL}$, and the PSA level was $2.4 \pm 2.2 \mathrm{ng} / \mathrm{mL}$.

Total IPSS decreased from $16.2 \pm 6.5$ at baseline to $8.2 \pm 7.0$ points 3 months later $(\mathrm{P}<0.001)$ (Table 2$)$. The total voiding score, the total storage score and the quality of life score were also significantly decreased. Maximum flow rate increased from $10.3 \pm 3.8 \mathrm{~mL} / \mathrm{sec}$ to $15.3 \pm 4.9 \mathrm{~mL} / \mathrm{sec}$ following silodosin treatment, although the changes in postvoid residual urine volume did not reach statistical significance.

Table 3 shows the visual function at baseline and 3 months after silodosin treatment. There were no significant differences in distant visual acuity, refractive error (spherical and cylinder), intraocular pressure, and angle of deviation (far and near). Baseline near visual acuity of right, left and both eyes were $0.47 \pm 0.36,0.41 \pm 0.37,0.27 \pm 0.26 \log \mathrm{MAR}$, respectively. After administration of silodosin for 3 months the near visual acuity of right eye and both eyes were improved to $0.38 \pm 0.39 \log$ -
MAR $(\mathrm{P}=0.018)$ and $0.21 \pm 0.27 \operatorname{logMAR}(\mathrm{P}=0.043)$, respectively. Near visual acuity of left eye also improved to $0.31 \pm 0.34$ $\operatorname{logMAR}$, which almost reached statistical significance $(\mathrm{P}=$ 0.068 ). Pupil size under room light decreased significantly in both eyes (right, $3.77 \pm 0.60$ vs. $3.16 \pm 0.58, \mathrm{P}=0.001$; left, $3.72 \pm$ 0.80 vs. $3.21 \pm 0.75, P=0.002$ ). Near stereoacuity improved in 7 of 15 patients (47\%), whereas 6 patients remained unchanged. The overall near stereoacuity measured with the Titimus Fly tended to improve from a median of 200 to $100 \mathrm{arcsec}$, but was not statistically significant $(\mathrm{P}=0.329)$.

In terms of subjective assessment of near visual ability and satisfaction, the Rasch score at NAVQ-10 improved from $54.7 \pm 9.9$ to $48.5 \pm 11.2(\mathrm{P}=0.004)$ (Table 1$)$. Especially, question item 1 (reading newspaper article/items on a menu), item 3 (reading mail/bill) and item 6 (seeing display/mobile) showed significant improvement. Two patients did not respond to the question of overall improvement of near vision after treatment (item 11), while 2 of 13 patients (15.4\%) showed no change, 5 patients (38.4\%) had little change, 4 (30.8\%) revealed moderate changes, and 2 (15.4\%) showed marked change.

\section{DISCUSSION}

This study was prompted by the need to validate anecdotal clinical observations regarding improvement of near visual function after treatment with silodosin [8]. In this prospective observational study, we found a significant increase in near vision, quality of life score in near visual activity, and decrease in pupil

Table 2. Change in lower urinary tract symptom-related variables after silodosin treatment for 3 months

\begin{tabular}{|c|c|c|c|c|c|}
\hline \multirow{2}{*}{ Variable } & \multicolumn{2}{|c|}{ Baseline } & \multicolumn{2}{|c|}{3 Months } & \multirow{2}{*}{ P-value ${ }^{a)}$} \\
\hline & Mean \pm SD & Median (IQR) & Mean \pm SD & Median (IQR) & \\
\hline \multicolumn{6}{|l|}{ IPSS } \\
\hline Voiding symptoms sum & $10.8 \pm 4.0$ & $9.0(8.0-14.0)$ & $5.0 \pm 4.4$ & $4.0(2.0-6.0)$ & $<0.001$ \\
\hline Storage symptoms sum & $5.4 \pm 3.0$ & $5.0(3.0-7.0)$ & $3.3 \pm 2.8$ & $3.0(1.0-4.0)$ & 0.002 \\
\hline Total scores & $16.2 \pm 6.5$ & $14.0(11.0-21.0)$ & $8.2 \pm 7.0$ & $7.0(4.0-11.0)$ & $<0.001$ \\
\hline QoL scores & $4.1 \pm 1.3$ & $4.0(3.0-5.0)$ & $2.5 \pm 1.5$ & $2.0(2.0-4.0)$ & 0.001 \\
\hline OABSS & $4.0 \pm 2.3$ & $3.0(2.0-6.0)$ & $2.7 \pm 2.1$ & $2.0(1.0-4.0)$ & 0.003 \\
\hline \multicolumn{6}{|l|}{ Uroflowmetry } \\
\hline Maximum flow rate $(\mathrm{mL} / \mathrm{sec})$ & $10.3 \pm 3.8$ & $10.0(7.0-13.0)$ & $15.3 \pm 4.9$ & $15.0(10.0-20.0)$ & 0.002 \\
\hline Postvoid residual urine volume (mL) & $30.7 \pm 39.3$ & $20.0(0.0-50.0)$ & $17.3 \pm 21.9$ & $10.0(0.0-30.0)$ & 0.051 \\
\hline
\end{tabular}

SD, standard deviation; IQR, interquartile range; IPSS, International Prostate Symptom Score; QoL, quality of life; OABSS, overactive bladder symptom score.

${ }^{\text {a)}}$ P-values were determined using Wilcoxon signed-rank test. 
Table 3. Changes in visual function following 3 months of silodosin treatment

\begin{tabular}{|c|c|c|c|c|c|}
\hline \multirow{2}{*}{ Variable } & \multicolumn{2}{|c|}{ Baseline } & \multicolumn{2}{|c|}{3 Months } & \multirow{2}{*}{ P-value ${ }^{a}$} \\
\hline & Mean \pm SD & Median (IQR) & Mean \pm SD & Median (IQR) & \\
\hline \multicolumn{6}{|l|}{ Distant visual acuity (logMAR) } \\
\hline Right & $0.28 \pm 0.40$ & $0.13(0.00-0.47)$ & $0.26 \pm 0.38$ & $0.13(0.00-0.40)$ & 0.465 \\
\hline Left & $0.22 \pm 0.36$ & $0.05(0.00-0.30)$ & $0.18 \pm 0.33$ & $0.02(0.00-0.22)$ & 0.066 \\
\hline Both & $0.14 \pm 0.31$ & $0.00(0.00-0.11)$ & $0.13 \pm 0.31$ & $0.00(0.00-0.07)$ & 0.655 \\
\hline \multicolumn{6}{|l|}{ Spherical error (diopter) } \\
\hline Right & $0.15 \pm 1.84$ & $0.00(-0.50-1.50)$ & $0.07 \pm 1.73$ & $0.00(-0.50$ to 1.50$)$ & 0.262 \\
\hline Left & $0.12 \pm 1.83$ & $0.00(-0.50-1.50)$ & $0.07 \pm 1.69$ & $0.00(-0.50$ to 1.00$)$ & 0.705 \\
\hline \multicolumn{6}{|l|}{ Cylindrical error (diopter) } \\
\hline Right & $-0.58 \pm 0.50$ & $-0.50(-0.75$ to 0.00$)$ & $-0.63 \pm 0.52$ & $-0.50(-1.00$ to -0.25$)$ & 0.705 \\
\hline Left & $-0.35 \pm 0.44$ & $-0.25(-0.50$ to 0.00$)$ & $-0.50 \pm 0.53$ & $-0.50(-0.50$ to 0.00$)$ & 0.180 \\
\hline \multicolumn{6}{|l|}{ Intraocular Pressure (mmHg) } \\
\hline Right & $14.67 \pm 2.44$ & $15.00(13.00-17.00)$ & $14.13 \pm 2.77$ & $13.00(12.00-17.00)$ & 0.276 \\
\hline Left & $14.33 \pm 3.11$ & $14.00(12.00-17.00)$ & $14.20 \pm 3.03$ & $13.00(12.00-17.00)$ & 0.858 \\
\hline Distant angle of deviation (PD) & $0.80 \pm 1.79$ & $0.00(0.00-2.00)$ & $0.80 \pm 1.79$ & $0.00(0.00-2.00)$ & 1.000 \\
\hline Near angle of deviation (PD) & $1.670 \pm 2.66$ & $0.00(0.00-4.50)$ & $2.33 \pm 2.66$ & $2.00(0.00-4.50)$ & 0.317 \\
\hline \multicolumn{6}{|l|}{ Near visual acuity (logMAR) } \\
\hline Right & $0.47 \pm 0.36$ & $0.40(0.19-0.70)$ & $0.38 \pm 0.39$ & $0.25(0.07-0.57)$ & $0.018^{*}$ \\
\hline Left & $0.41 \pm 0.37$ & $0.30(0.16-0.57)$ & $0.31 \pm 0.34$ & $0.30(0.07-0.40)$ & 0.068 \\
\hline Both & $0.27 \pm 0.26$ & $0.24(0.14-0.30)$ & $0.21 \pm 0.27$ & $0.19(0.00-0.30)$ & $0.043^{*}$ \\
\hline \multicolumn{6}{|c|}{ Pupil size under the room light (mm) } \\
\hline Right & $3.77 \pm 0.60$ & $3.90(3.50-4.20)$ & $3.16 \pm 0.58$ & $3.10(2.75-3.73)$ & $0.001^{*}$ \\
\hline Left & $3.72 \pm 0.80$ & $3.60(3.30-4.40)$ & $3.21 \pm 0.75$ & $3.10(2.83-3.68)$ & $0.002^{*}$ \\
\hline Near Stereoacuity $(\operatorname{arcsec})^{\mathrm{b})}$ & $200(400-65)$ & & $100(350-50)$ & & 0.329 \\
\hline
\end{tabular}

$\mathrm{SD}$, standard deviation; IQR, interquartile range; MAR, minimal angle resolution; $\mathrm{PD}$, prism diopter.

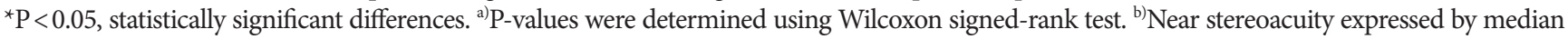
value and IQR.

size under room light after treatment with silodosin for 3 months. No patient reported ocular side effects such as decrease in contrast sensitivity and field constriction due to decreased pupil size during day time. Only one patient reported worsening of near vision quality in the questionnaire.

Alpha-adrenergic antagonists such as silodosin are known to affect visual function. Intraoperative (intraoperative floppy iris syndrome, IFIS) during eye surgery is a well-known side effect of treatment with alpha-adrenergic antagonist [17]. The association of tamsulosin, which is another selective alpha-1A adrenergic antagonist has been shown in numerous prior studies [18]. Recent head-to-head studies comparing tamsulosin and alfuzosin indicated that IFIS was 30 times more frequent and more severe in patients treated with tamsulosin, because of its high affinity and selectivity for the alpha-1A adrenergic receptor [19].

Silodosin is a highly selective alpha-1A adrenergic antagonist and also associated with IFIS $[9,20]$. Silodosin showed a 56-fold selectivity for the a1A versus a1D subtype and a 583-fold selectivity for the a1A vs. a1B subtype [9]. Silodosin showed higher selectivity for the alpha-1A adrenergic receptor subtype than tamsulosin [21]. Although tamsulosin is also regarded as an alpha-1A selective agent, a receptor-binding study showed that the subtype selectivity ( $a 1 \mathrm{~A} / \mathrm{a} 1 \mathrm{~B})$ of silodosin was 162, which was far higher than that of tamsulosin (9.55) [21]. The higher selectivity of silodosin might induce greater constriction of pupil.

In the eye, alpha- 1 adrenergic receptors exist in the inner and 

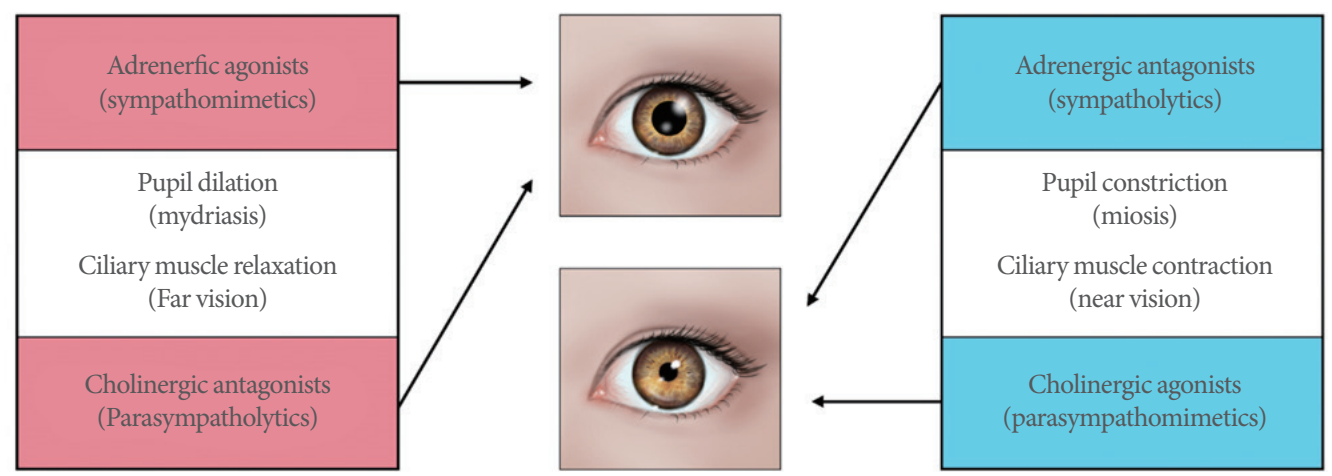

Fig. 1. Sympathetic (adrenergic) and parasympathetic (cholinergic) effect on the pupil and ciliary muscles.

outer portions of the ciliary muscle [10]. Adrenergic agonists (sympathomimetics) and cholinergic antagonists (parasympatholytics) are involved in (1) pupil dilation (mydriasis) and (2) ciliary muscle relaxation, whereas adrenergic antagonists (sympatholytics) and cholinergic agonists (parasympathomimetics) play a role in pupil constriction (miosis) and ciliary muscle contracture, which allows the lens to thicken and accommodate near vision (Fig. 1) [13]. The depth of focus is inversely proportional to pupil diameter. Increased depth of focus facilitates limited tolerance of the eye to out-of-focus images. Thus, the small pupil exhibits larger acceptable field of depth [14]. This pharmacologic evidence supports the role of silodosin for near vision improvement in a presbyopic patient.

With regard to changes in the pupil size, the results of present study are similar to previous studies assessing pupil dynamics following exposure to alpha-1 adrenergic antagonists [22-24]. Altan-Yaycioglu et al. [23] reported decreases in pupil size under room light in patients treated with tamsulosin. Theodossiadis et al. [24] suggested a decrease in maximum pupillary diameter by $0.50 \mathrm{~mm}$ and $0.49 \mathrm{~mm}$ in patients treated with tamsulosin and alfuzosin, respectively.

We did not identify reasons of significant concern involving ciliary muscle contraction when patients were treated with silodosin for 3 months. Ciliary muscle contraction allows the lens to thicken, which results in myopic shift of spherical error (towards more negative value). In the present study, there was no minus shift in spherical error of both eyes, which was consistent with a previous study by Jensen, who reported no significant effects on the rate of myopia in young school children exposed to topical adrenergic receptor antagonist (timolol maleate) over a 2 -year period [25]. Thus, the present and previous findings together would appear to discount a link between systemic thera- py using apha-1 adrenergic antagonists and myopic shift mediated by sustained contraction of ciliary muscle.

Considering that treatment with alpha-1A adrenergic antagonist had no association with myopic shift, it is plausible that a pinhole effect (increased depth of focus) due to constricted pupil size resulted in improved near vision instead of ciliary muscle contraction. Also, the small pupil provides partial tolerance to residual astigmatism, which led to improved image quality without decreasing stereoacuity and contrast sensitivity [26].

However, caution is needed when interpreting the overall results. There was a decrease of 0.1 unit on the logMAR scale, which indicates a one-line increase on the visual acuity chart. Although our findings suggest significant near vision improvement after taking silodosin, it should be noted that the measurement of visual acuity is subjective response and varies with the examiner and the test conditions. NAVQ-10 is a standardized questionnaire designed for the subjective assessment of near visual ability and satisfaction in patients with presbyopia. The Rasch NAVQ score improved from $54.7 \pm 9.9$ to $48.5 \pm 11.2$. Eleven cases of patients (73\%) showed improved NAVQ score. However, the measurement error in the survey question of near vision QoL should be considered. This response bias might arise from interaction between the interviewer and the respondent as the respondents may answer to please the interviewer rather than provide an honest response.

However, the description provided by several patients about their near vision show dramatically improving response. We did not report the results because it was not included in the primary outcome of this study design. Two patients reported that they were able to read small letters on the smart phone and computer monitor without taking off their distant-vision glasses after taking silodosin, as before. One of the patients stated 
that he does not use near glasses anymore when working with a computer monitor. These findings suggest that the subset of patients showed remarkable improvement following silodosin treatment, obviating the need for corrective glasses.

We recognize the limitations of this study. First, the number of participants was small. Also, several patients withdrew their consent to participate in the study because of the long test times. Second, the relatively short duration of follow-up and the nonrandomized and nonmasked study design was another limitation of this study. Because we patients were selected based on silodosin treatment for LUTS, a randomized controlled study was not performed. Third, we did not assess the near vision accommodation and pupil size with fixation at distance. Additional evaluation using dynamical accommodation and pupil size recording instruments will be needed to verify the results of this study. Finally, we mainly investigated the effect of silodosin on near visual function. The alpha-1A adrenergic receptors also exist in the choroid and retina as well as iris and ciliary body. Previous studies have demonstrated that alpha-1A adrenergic antagonists increased the choroidal thickness [27]. Thus, a future study will be needed to determine the association between near visual function and other ocular changes such as retina and choroid. Nonetheless, this is the first prospective study providing possible evidence linking silodosin to near vision improvement.

In conclusion, silodosin treatment in some patients with LUTS/BPH improves near vision. Decrease in pupil size caused by the inhibition of adrenergic contraction of iris dilator muscle might be the mechanism underlying improved near vision. A future randomized, double-masked study with a larger number of presbyopic patients may be warranted to confirm the association between near vision and treatment with various types of alpha-1 adrenergic antagonists.

\section{ORCID}

$\begin{array}{ll}\text { Hyun Jin Shin } & 0000-0002-3563-8042 \\ \text { Woo Suk Choi } & 0000-0002-8352-578 X \\ \text { Shin-Hyo Lee } & 0000-0001-7031-7722 \\ \text { Andrew G. Lee } & 0000-0002-2473-299 X \\ \text { Aram Kim } & 0000-0002-2055-2262 \\ \text { Hyoung Keun Park } & 0000-0001-7606-4180 \\ \text { Sung Hyun Paick } & 0000-0002-6010-3277 \\ \text { Hyeong Gon Kim } & 0000-0002-5034-5299\end{array}$

\section{AUTHOR CONTRIBUTION STATEMENT}

- Conceptualization: HJS, WSC

- Data curation: HJS, WSC, AK

- Formal analysis: HJS, WSC, HKP

- Funding acquisition: WSC, HGK

- Methodology: HJS, WSC, AK

- Project administration: SHP

- Visualization: $S L$

-Writing-original draft: HJS, WSC

-Writing-review \& editing: HJS, WSC, AGL, HGK

\section{REFERENCES}

1. Cai T, Wang N, Liang L, Zhou Z, Zhang Y, Cui Y. Meta-analysis of the efficacy of imidafenacin for overactive bladder induced by benign prostatic hyperplasia in men receiving alpha-blocker therapy. Int Neurourol J 2020;24:365-74.

2. Berry SJ, Coffey DS, Walsh PC, Ewing LL. The development of human benign prostatic hyperplasia with age. J Urol 1984;132:474-9.

3. Kim KS, Jo JK, Lee JA, Choi BY, Moon HS. Do lifestyle factors affect lower urinary tract symptoms? Results from the Korean community health survey. Int Neurourol J 2019;23:125-35.

4. Wolffsohn JS, Davies LN. Presbyopia: effectiveness of correction strategies. Prog Retin Eye Res 2019;68:124-43.

5. Durr NJ, Dave SR, Lage E, Marcos S, Thorn F, Lim D. From unseen to seen: tackling the global burden of uncorrected refractive errors. Annu Rev Biomed Eng 2014;16:131-53.

6. Gualdi L, Gualdi F, Rusciano D, Ambrósio R Jr, Salomão MQ, Lopes B, et al. Ciliary muscle electrostimulation to restore accommodation in patients with early presbyopia: preliminary results. J Refract Surg 2017;33:578-83.

7. Fricke TR, Tahhan N, Resnikoff S, Papas E, Burnett A, Ho SM, et al. Global prevalence of presbyopia and vision impairment from uncorrected presbyopia: systematic review, meta-analysis, and modelling. Ophthalmology 2018;125:1492-9.

8. Choi WS, Cho MC, Lee JW, Song SH, Oh JK, Lee SW, et al. Efficacy and safety of silodosin in the treatment of lower urinary tract symptoms in elderly men taking antihypertensive medications. Prostate Int 2017;5:113-8.

9. Kim YJ, Tae BS, Bae JH. Cognitive function and urologic medications for lower urinary tract symptoms. Int Neurourol J 2020;24: 231-40.

10. Wikberg-Matsson A, Uhlén S, Wikberg JE. Characterization of alpha(1)-adrenoceptor subtypes in the eye. Exp Eye Res 2000;70: 
51-60.

11. Konno F, Takayanagi I. Characterization of postsynaptic alpha 1 -adrenoceptors in the rabbit iris dilator smooth muscle. Naunyn Schmiedebergs Arch Pharmacol 1986;333:271-6.

12. Suzuki F, Taniguchi T, Nakamura S, Akagi Y, Kubota C, Satoh M, et al. Distribution of alpha-1 adrenoceptor subtypes in RNA and protein in rabbit eyes. Br J Pharmacol 2002;135:600-8.

13. Schwinn DA, Afshari NA. al-Adrenergic receptor antagonists and the iris: new mechanistic insights into floppy iris syndrome. Surv Ophthalmol 2006;51:501-12.

14. Charman WN, Whitefoot H. Pupil diameter and the depth of field of the human eye as measured by laser speckle. Optica Acta 1977; 24:1211-6.

15. Gupta N, Wolffsohn JS, Naroo SA, Davies LN, Gibson GA, Shah S. Development of a near activity visual questionnaire to assess accommodating intraocular lenses. Cont Lens Anterior Eye 2007; 30:134-43.

16. Buckhurst PJ, Wolffsohn JS, Gupta N, Naroo SA, Davies LN, Shah S. Development of a questionnaire to assess the relative subjective benefits of presbyopia correction. J Cataract Refract Surg 2012;38: 74-9.

17. Enright JM, Karacal H, Tsai LM. Floppy iris syndrome and cataract surgery. Curr Opin Ophthalmol 2017;28:29-34.

18. Leibovici D, Bar-Kana Y, Zadok D, Lindner A. Association between tamsulosin and intraoperative "floppy-iris" syndrome. Isr Med Assoc J 2009;11:45-9.

19. Chang DF, Campbell JR, Colin J, Schweitzer C; Study Surgeon Group. Prospective masked comparison of intraoperative floppy iris syndrome severity with tamsulosin versus alfuzosin. Ophthalmology 2014;121:829-34.

20. Ipekci T, Akin Y, Hoscan B, Tunckiran A. Intraoperative floppy iris syndrome associated with silodosin. Acta Ophthalmol 2015;93: e306.

21. Tatemichi S, Kobayashi K, Maezawa A, Kobayashi M, Yamazaki Y, Shibata N. Alpha1-adrenoceptor subtype selectivity and organ specificity of silodosin (KMD-3213). Yakugaku Zasshi 2006;126: 209-16.

22. Neff KD, Sandoval HP, Fernández de Castro LE, Nowacki AS, Vroman DT, Solomon KD. Factors associated with intraoperative floppy iris syndrome. Ophthalmology 2009;116:658-63.

23. Altan-Yaycioglu R, Yaycioglu O, Gul U, Pelit A, Adibelli FM, Akova YA. The effects of two systemic alphal-adrenergic blockers on pupil diameter: a prospective randomized single-blind study. Naunyn Schmiedebergs Arch Pharmacol 2007;375:199-203.

24. Theodossiadis PG, Achtsidis V, Theodoropoulou S, Tentolouris N, Komninos C, Fountas KN. The effect of alpha antagonists on pupil dynamics: implications for the diagnosis of intraoperative floppy iris syndrome. Am J Ophthalmol 2012;153:620-6.

25. Jensen H. Myopia progression in young school children. Acta Ophthalmologica 1991;200(Suppl):1-79.

26. Bonaque-González S, Ríos-Rodríguez S, López-Gil N. Improving vision by pupil masking. Biomed Opt Express 2016;7:2538-50.

27. Sari E, Sari ES, Yazici A, Koç A, Bulbul E, Koytak A, et al. The effect of systemic tamsulosin hydrochloride on choroidal thickness measured by enhanced depth imaging spectral domain optical coherence tomography. Curr Eye Res 2015;40:1068-72. 